\begin{tabular}{|c|c|c|}
\hline GE) & $x^{2}+4$ & \\
\hline 8 & 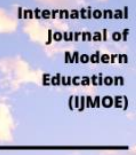 & $\begin{array}{c}\text { INTERNATIONAL JOURNAL OF } \\
\text { MODERN EDUCATION } \\
\text { (IJMOE) }\end{array}$ \\
\hline & oliss: 2637.0005 & www.ijmoe.com \\
\hline
\end{tabular}

\title{
EXPLORING STUDENTS BEHAVIOUR IN USING GOOGLE CLASSROOM DURING COVID-19 PANDEMIC: UNIFIED THEORY OF ACCEPTANCE AND USE OF TECHNOLOGY (UTAUT)
}

\author{
Rahayu Mokhtar ${ }^{1 *}$, Mohd Hyrul Abu Karim² \\ 1 Department of Hotel Operations, Selayang Community College (KKSY), Malaysia. \\ Email: rahayu@kkselayang.edu.my \\ 2 Department of Hotel Operations, Selayang Community College (KKSY), Malaysia. \\ Email: hyrul@kkselayang.edu.my \\ Corresponding Author
}

\section{Article Info:}

\section{Article history:}

Received date: 03.01.2021

Revised date: 02.02.2021

Accepted date: 28.02 .2021

Published date: 10.03.2021

To cite this document:

Mokhtar, R., \& Karim, M. H. A. (2021). Exploring Students Behaviour in Using Google Classroom During Covid-19 Pandemic: Unified Theory of Acceptance and Use of Technology (UTAUT). Journal of Modern Education, 3(8), 182-195.

DOI: 10.35631/IJMOE.380015

This work is licensed under CC BY 4.0

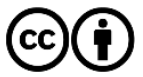

\begin{abstract}
:
Covid-19 pandemic has become one of the reasons for online education became an important area to explore worldwide nowadays. Google Classroom has popularly chosen by online educators to empower the teaching and learning process. However, limited research discussed the student's acceptance and students' use behaviour using Google Classroom among Community College students in Malaysia. Since the worldwide have been affected by pandemic covid-19, the educators need to run the classes online, including subjects that related to the technical and vocational. Thus, this study adapted the Unified Theory of Acceptance and Use of Technology (UTAUT) model to understand the relationship between the five predictors in the framework in creating the student behaviour to use Google Classroom application in the learning process. Data were derived from an online survey involving 293 students from seven Malaysian Community colleges and been analysed using Statistical Package Social Science (SPSS) version 26.0. Findings from this study indicate that effort expectancy is the most significant dimension that influences behaviour intention, followed by social expectancy and performance expectancy. In addition, student's use behaviour has been significantly influenced by the behaviour intention and facilitating conditions support by the college lecturers. Although there is a moderating effect shown in the relationships between performance expectancy and effort expectancy, yet it not supported in the link of social influence with behaviour intention and facilitating conditions with students' user behaviour. The results provide useful insight on the acceptance and use of Google Classroom among Malaysian Community College students. It is hoped that results from this study can be used as a guideline for educators to focus on and strategize their teaching methods and adapt to a new norm teaching environment.
\end{abstract}




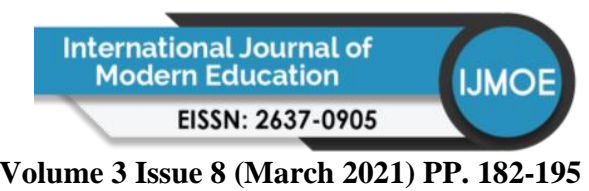

Volume 3 Issue 8 (March 2021) PP. 182-195

DOI: 10.35631/IJMOE.380015

Keywords:

Education, Student Behaviour, Malaysia Community College, UTAUT, Voluntariness Of Use

\section{Introduction}

Nowadays, the world has been affected by Covid-19 pandemic, as well as higher education. This situation gives impacts towards the increasing of integration in the e-learning systems in teaching and learning process. E-learning systems allow students to utilise the internet to access learning products, engage with materials, instructors, as well as other learners. However, there is a challenge for educators to run the classes thru online, either for theory subjects or technical and vocational subjects. At this moment educators have to be very creative to look into the beauty of technology. Technology can be applied into various types of medium, including internet, web sites as well as mobile technology. There are number of previous studies on technology discussed from the perspective of retail, banking as well as education (Williams, Rana, \& Dwivedi, 2015). In the retail industry, technology has evolving the customer needs and preferences through online shopping and online shops, mobile payment, and internet banking facilitates (Mohd Ariffin, Ahmad, \& Haneef, 2020; Rahi, Abd. Ghani, Alnaser, \& Ngah, 2018; Tran, 2019)

In Almaiah, Alamri and Al-Rahmi (2019) and Liu, Maimaitijiang, Gu, Zhong, Zhou, Wu and Hao (2019), scholars agreed that large numbers of the higher institutions starting and been forced to use technology to deliver the learning process to the students in the education system. The reason is the technology could enhance the education systems. It became as one of the solutions for the educators in facing the Covid-19 pandemic. However, the educators need to take urgent action to understand e-learning and implement the systems. It could effect on the teaching approach and assessment procedures. Teaching method has experienced the changes and mobile-learning is one of the recent technologies that become as one of the $p$ for teaching tools, known as mobile learning (m-learning). M-learning has become one of the popular technology in education. Chao (2019), defined m-learning as the learning process that could be conducted across various contexts such as location, time, and other environmental factors where learners can benefit by using various smart mobile devices, including smartphones and tablet computers. M-learning enables to provide the learning materials, activities and university services for students in actual time (Almaiah et al., 2019). Therefore, Liu, et al. (2019) suggested that the mobile application is suggested suitable for the education system.

Google Classroom is one of the learning applications that simplify the interactions between students and educators, it is also a convenient method of distributing and rating tasks and assessments (Raman, Singh, Rathakrishnan \& Ismail, 2020). Besides that, Google Classroom can be accessed using any technology devices, such as laptop, smartphone as well as tablet (Abd Manan \& Hanafi, 2019). Malaysia Community College committed with the integration of technology and learning process, therefore, provides each of the educators and students with the individual email that allows them to access Google Suite as well as Google Classroom. Aforementioned, the educators would share the teaching materials in the Google Classroom, whereas, the students could access it anytime and anywhere. The research on the 


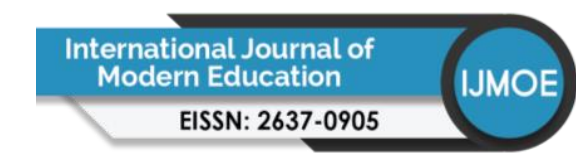

Volume 3 Issue 8 (March 2021) PP. 182-195 DOI: 10.35631/IJMOE.380015

effectiveness of using Google Classrooms for education was examined by other previous studies (Abd Manan \& Hanafi, 2019; Al-Maroof \& Al-Emran, 2018; Kumar \& Bervell, 2019)

The covid-19 pandemic have been affected including the education system (Raza, Qazi, Khan, \& Salam, 2020). In order to reduce the high infectious disease, the education institutions are not allowed to run the face to face classes, tutorials as well as practical classes. Consequently, online classes are the only option to continue classes. For Malaysia Community College, since Google Classroom has been provided, the educators and students need to adapt to the new norm environment to ensure the courses learning outcome delivered in the respective semester. Chao (2019) suggested that technology could help students to study anytime and anywhere. However, sometimes students have difficulties in dealing with technology, particularly usage and acceptance by students (Kaliisa, Palmer \& Miller, 2019). Thus, to ensure the student could adapt to the situation, the use and acceptance of the student are critical to be examined. In response to the use and acceptance of user in using technology, Venkatesh, Morris, Davis and Davis (2003) developed a theory known as the Unified Theory of Acceptance and Use of Technology (UTAUT). The theory suggested the individual reactions in using information technology, namely performance expectancy, effort expectancy; social influence and facilitating conditions could influence the intention to use the technology, as well as the actual use of the technology. Since that, number of studies proved that UTAUT to be a valid model to predict the use and acceptance of technology among the user.

\section{Literature Reviews}

\section{Google Classroom}

As a response to the covid-19 crisis, the educators worldwide have to immediately switch the way of teaching to the new norm education approach. Surprisingly, most of the conventional or vocational educators have to face it for the first time in their career. Google Classroom is one of technology chosen by the educators and becomes the medium interactions between students and educators. Google Classroom offers free web service developed by Google for schools and education institutions that aims to simplify creating, distributing and grading assignments (Okmawati, 2020). Abd Manan and Hanafi (2019) suggested that Google Classroom improves the communication between students and teachers, as well as, increasing the student's performance in the class. Al-Maroof and Al-Emran (2018) and Kaliisa et al. (2019) suggested that there is a need to investigate the behaviour intention and the acceptance of the student in using Google Classroom.

Raman et al. (2020) had listed a number of activity that could be conducted via Google Classroom, for instance, peer editing on study papers, project capstone, course evaluations, online discussion, distributes notes to students and fellow educators, disperse students homework, contact with students via chat and comments, flipped classroom, document storage, quizzes, return students assessment and video clip galleries. Since most of the previous studies focused more on the students from the universities, yet, a limited number of studies discuss from the perspective of Malaysia Community College. Since Covid-19 pandemic spread out, researchers started to study the effectiveness of Google Classrooms in the teaching and learning process. Okmawati (2020) proved that Google Classroom positively attract students. However, there are identified some barriers during online learning using Google Classroom (Octaberlina \& Muslimin, 2020). Thus, this study is carried out to identify 


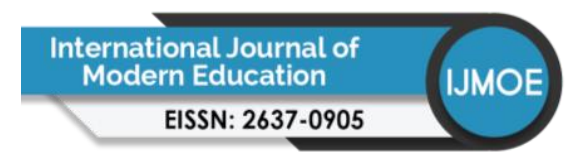

Volume 3 Issue 8 (March 2021) PP. 182-195

DOI: 10.35631/IJMOE.380015

the factors that influence the student behaviours in using Google Classroom, from the perspective of the Malaysia Community College students.

\section{Unified Theory of Acceptance and Use of Technology (UTAUT)}

UTAUT was developed by Venkatesh et al. (2003) through a review and consolidation of eight models such as Theory Reasoned Action, Technology Acceptance model, motivational model, Theory of Planned Behaviour, Model of Personal Computer Use, Diffusion Innovation Theory, Social Cognitive Theory and combination model of TPB and TAM. In addition, the author explains that $70 \%$ of the variance in user intention can be predicted by the UTAUT Model. Based on previous literature, Chao (2019) mentioned that the UTAUT model is the most effective model for analysing technology acceptance. In the UTAUT model proposed by Almaiah et al. (2019), they extend the model by integrating new constructs represented by a few questions and the scores for the constructs can be mapped and interrelated. Han and Conti (2020) combined the UTAUT model with Post Acceptance Model (PAM) in their study to gain a clear difference before and after actual use. In this study, UTAUT is will be measured using expectancy, effort expectancy, social influence, facilitating conditions towards behavioural intention of the students to use Google Classroom in the learning process, furthermore the moderating effects of voluntariness of use.

\section{Performance Expectancy (PE)}

According to Venkatesh et al. (2003), performance expectancy defined as the extent to which technology benefits the user when carrying out a specific activity. Besides, the authors found that $\mathrm{PE}$ is the strongest determinant of a user's behavior intention to adopt a technology. In line with it, Jayaseelan, Koothoor and Pichandy (2020) was found that performance expectancy is a chief factor in predicting the intention of adopting ICT in profession. In Chao (2019), PE has been defined as the degree to which an individual believes that the system helps to improve job performance. Abd Manan and Hanafi (2019) explained that performance expectancy as the confidence level of the student who uses Google Classroom that it can increase their study performance. From the context of m-learning, Almaiah et al. (2019) found that performance expectancy has a significant effect on behavioural intention. Number of studies agreed that performance expectancy has a significant relationship with behaviour intention (Almaiah et al., 2019; Arumugam Raman et al., 2020; Chao, 2019; Padhi, 2018; Rabaa'i, 2017). Based on that, it is proposed that:

H1: Performance expectancy has a relationship with the students' behaviour intention

\section{Effort Expectancy $(E E)$}

According to Venkatesh et al. (2003), EE is the degree of ease associated with the use of the system. In recent studies, Jayaseelan et al. (2020) defined EE as the degree to which a person considers it easy to use a specific system becomes the yardstick of its success. Despite performance expectancy, effort expectancy has been suggested as the main dimension in the UTAUT (Chao, 2019; Venkatesh, Morris, Davis, \& Davis, 2003). There are several studies discussed the effort expectancy on mobile learning. Previous study by Chao (2019) described from the perspective of the student, the effort expectancy is related to the ease of use of mobile learning. The easier to use the technology, the higher possibility of being accepted (Kaliisa et al., 2019). For instance, effort expectancy described as the facilities related to Google Classroom (Abd Manan \& Hanafi, 2019). The effort expectancy is identified as the factors that influence the student's behavioural intention in using mobile learning (Almaiah et al., 2019). Therefore, the significant effort expectancy needs to be examining because it will 


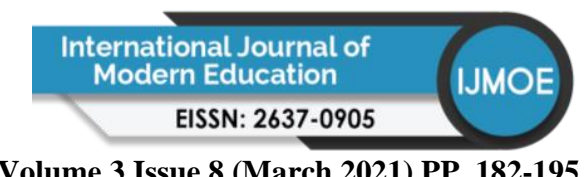

Volume 3 Issue 8 (March 2021) PP. 182-195 DOI: 10.35631/IJMOE.380015

be significant in determining the student intention. Previous studies indicate that effort expectancy has a significant effect on behavioural intention (Chao, 2019; Kumar \& Bervell, 2019; Rabaa'i, 2017; Raman et al., 2020). However, the insignificant relationship between EE and behaviour intention was found in Salloum and Shaalan (2018). Thus, it is worth to find an answer for this specific study. It is proposed that:

H2: Effort expectancy has a relationship with the students' behaviour intention

\section{Social Influence (SI)}

Venkatesh et al. (2003) defined SI as the degree to which an individual perceives that important others believe he or she should use the system. From the perspective of Google Classroom, social influence could be defined as the students have confidence in that people who important to them believe that they need to use Google Classroom (Abd Manan \& Hanafi, 2019). Gruzd, Staves and Wilk (2012) and Kaliisa et al. (2019), agreed that social influences play an important and positive role for someone to decide to use technology, specifically regarding mobile learning. However, the study by Almaiah et al. (2019) identified that social influence does not influence the student's behavioural intention in using mobile learning. The contradictions in previous literature put the point to study that social influence is one of the factors that determine the student behaviour intention. According to Dwivedi et al. (2011), Liu et al. (2019), Raman and Rathakrishnan (2020) and Salloum and Shaalan (2018) social influence could encourage the intention to use the technology. Therefore, it is proposed that:

H3: Social influence has a relationship with the students' behaviour intention

\section{Behavioural Intention (BI) and Use Behaviour (UB)}

In Chao (2019), the scholar defined BI as the degree to which a person has formulated conscious plans regarding whether to perform a specified future behaviour. Venkatesh et al. (2003) identified that behavioural intention has a positive influence on the usage of technology, in line with Jayaseelan et al. (2020) stressed that behaviour intention was a major determinant of usage behavior. Almaiah et al. (2019) and Al-Maroof and Al-Emran (2018) found that behaviour intention gives a positive impact on the student behaviour, which is the actual use. Thus, in this study, behavioural intention defined as the behaviour intention to use, meanwhile, student behaviour is translated as the actual use behaviour of the student. The significant relationship between behaviour intention and use behaviour was found in many previous literature (Dwivedi et al., 2011; Jayaseelan et al., 2020; Rabaai', 2017; Raza, Qazi, Khan \& Salam, 2020; Salloum \& Shaalan, 2018). Therefore, it is proposed that:

H4: Behaviour intention has a relationship with student behaviour

\section{Facilitating Condition (FC)}

In recent studies, Jayaseelan et al. (2020) defined FC as the degree to which an individual believes that an organizational and technical infrastructure exists to support the use of the system. Consistent with Venkantesh et al. (2003), facilitating condition is defined as a user's perception of the disposable resources and support when performing a task. From the perspectives of education, the facilitating condition could be translated as the students belief themselves towards the availability of the technical infrastructures to support of technology, for instance, Google Classroom (Abd Manan \& Hanafi, 2019). Apart from that, facilitating condition also related to the actual use of the student in using mobile learning for education purposes (Almaiah et al., 2019). To ensure the student connected with their education, it is important to provide for the students the guidance and technical support that could improve 


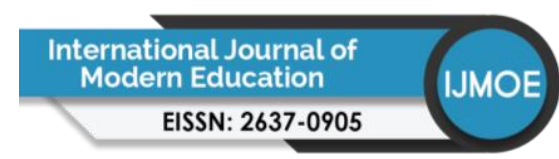

Volume 3 Issue 8 (March 2021) PP. 182-195 DOI: 10.35631/IJMOE.380015

the engagement with learning technologies (Mubuke, Masaba, Ogenmungu \& Kituyi, 2017). Since it could be related to the actual use, therefore, Kumar and Bervell (2019) proposed to enhance the content, activities and design of the Google Classroom to be more exciting and interactive. Yet, facilitating conditions should be one of the focuses for the educators to attract their students. Several scholars found that facilitating condition has a significant relationship with behaviour intention of the student (Almaiah et al., 2019; Kumar \& Bervell, 2019; Mubuke, Masaba, Ogenmungu, \& Kituyi, 2017). Similar to behavioural intention, this study also suggested that facilitating conditions could influence the student actual use of the Google Classroom. Therefore, it is proposed that:

H5: Facilitating condition has a relationship with student behaviour

\section{Voluntariness of Use (VOU) as Moderator Variable}

Voluntariness is the context in which the user will accept technology voluntarily (Ramayah, 2010). Voluntariness of Use is defined as the degree to which use of the innovation is perceived as being voluntary or of free will (Moore \& Benbasat, 1991). Venkatesh et al. (2003) have proposed to look at voluntariness as a moderator variable in the beliefs intention behavior. Result from their study found that the moderator effect increased from $35 \%$ without moderators to $53 \%$. There is no obligation on the user to accept the technology; therefore, we would like to test this notion in our research. Thus, the six hypothesis forwarded is as follows:

H6a: The positive relationship between performance expectancy and behaviour intention will be stronger for those with higher voluntariness of use

H6b: The positive relationship between effort expectancy and behaviour intention will be stronger for those with higher voluntariness of use

H6a: The positive relationship between social influence and behaviour intention will be stronger for those with higher voluntariness of use

H6a: The positive relationship between facilitation conditions and students use behaviour will be stronger for those with higher voluntariness of use

As previously mentioned, the UTAUT theory has been used in measuring student behaviour in using technology (Almaiah et al., 2019; Chao, 2019; Han \& Conti, 2020; Liu et al., 2019). Han and Conti (2020) conducted research that related to the robotics. Meanwhile, Liu et al. (2019) focussed on the intention of the student to use application that related to physical activity. Meanwhile, number of studies discussed the effectiveness of Google Classroom as the medium of technology use for education purposes (Abd Manan \& Hanafi, 2019; AlMaroof \& Al-Emran, 2018; Kumar \& Bervell, 2019; Raman et al., 2020). Therefore, it is proven that the model is widely adopted and applicable in measuring the student behaviour intention and actual use of technology. Based on the literature review, it has been observed that there are limited numbers that examine the factors determining student behaviour in using Google Classroom for Malaysian Community College. Since the Google Classroom has become as the medium between students and educators to communicate and deliver the course learning outcomes in covid-19 pandemic situation, therefore, this study examines the relationship of five (5) predictors of UTAUT in framework from the perspective of students of Malaysian Community College to use Google Classroom application in the learning process. This study also seeks the moderating effects of voluntariness of use in the UTAUT theory. 


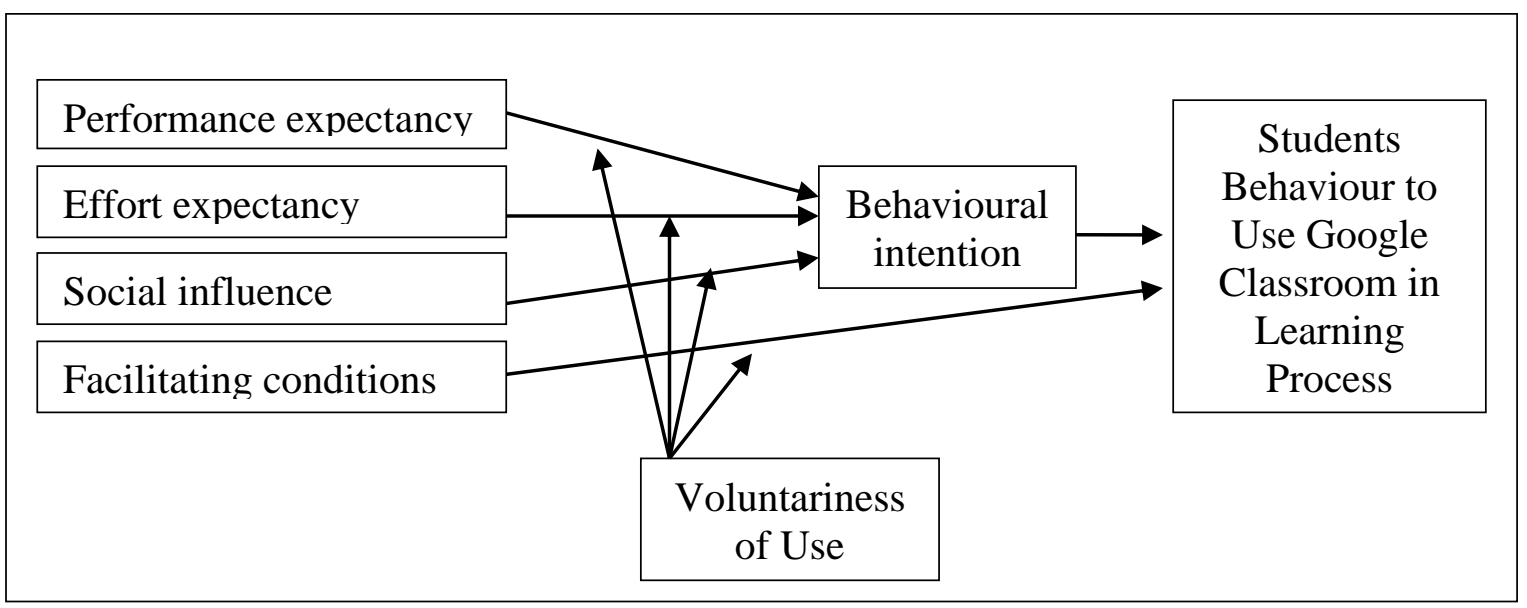

Figure 1: Research Model

Source: Adapted from Venkatesh et al. (2003).

\section{Methodology}

This study was designated to examine the factor determining the student in using Google Classroom. Data were derived from an online survey. Respondents were chosen using purposive sampling. As the intention of this study to tap the student behaviour, therefore, the survey was distributed to the students from seven Malaysia Community Colleges. The survey instrument consists of six sections consists that examined the respondent demographic information (Section A), performance expectancy (Section B), effort expectancy (Section C) and social influence (Section D). Meanwhile, Section E designed to measure facilitating conditions. The items in Section F designed to identify student behaviour to use Google Classroom in learning process. The questionnaires were measured by the five-point Likert scale. There are five alternative answers, 5-points strongly agree, 4-points agree, 3-points less agree, 2-points disagree, and 1-point strongly disagree. The questionnaire was adapted from Paul Van Schaik (2009).

\section{Table 1: Question Item}

\begin{tabular}{|c|c|c|}
\hline Construct & Items & Measures \\
\hline \multirow{4}{*}{$\begin{array}{l}\text { Performance } \\
\text { Expectancy }\end{array}$} & PE1 & I find Google Classroom application useful in my studies \\
\hline & PE2 & $\begin{array}{l}\text { Using Google Classroom application enables me to } \\
\text { accomplish tasks more quickly }\end{array}$ \\
\hline & PE3 & $\begin{array}{l}\text { Using Google Classroom application increases my } \\
\text { productivity }\end{array}$ \\
\hline & PE4 & $\begin{array}{l}\text { If I use Google Classroom application, I will increase my } \\
\text { chances of progressing in my studies }\end{array}$ \\
\hline \multirow[t]{3}{*}{ Effort Expectancy } & EE1 & $\begin{array}{l}\text { It is easy for me to become skilful at using Google } \\
\text { Classroom application }\end{array}$ \\
\hline & EE2 & I find Google Classroom application is easy to use \\
\hline & EE3 & $\begin{array}{l}\text { Learning to operate Google Classroom application is easy } \\
\text { for me }\end{array}$ \\
\hline Social Influence & SI1 & $\begin{array}{l}\text { People who influence my behaviour think that I should } \\
\text { use Google Classroom Application }\end{array}$ \\
\hline
\end{tabular}


Volume 3 Issue 8 (March 2021) PP. 182-195 DOI: 10.35631/IJMOE.380015

SI2 People who are important to me think that I should use Google Classroom application

\begin{tabular}{lll}
\hline $\begin{array}{l}\text { Facilitating } \\
\text { Conditions }\end{array}$ & FC1 & $\begin{array}{l}\text { Lecturer has been helpful in the use of Google Classroom } \\
\text { application } \\
\text { In general, the college has supported the use of Google } \\
\text { Classroom application }\end{array}$ \\
\hline $\begin{array}{l}\text { Behaviour } \\
\text { Intention }\end{array}$ & BI1 & $\begin{array}{l}\text { I intend to use Google Classroom application in my } \\
\text { studies } \\
\text { I predict I would use Google Classroom application in my } \\
\text { studies } \\
\text { I plan to use Google Classroom application in my studies }\end{array}$ \\
\hline BI2 & BI3 & $\begin{array}{l}\text { I find using Google Classroom application to be } \\
\text { enjoyable } \\
\text { The process of using Google Classroom application is } \\
\text { pleasant } \\
\text { I have fun using Google Classroom application }\end{array}$ \\
\hline
\end{tabular}

Source: Adapted from Paul Van Schaik (2009)

\section{Findings}

\section{Respondent profile}

Online survey was conducted and a total of 293 students responded to the questionnaire. Among the students contacted with the help of their lecturers, the response rate was 59.3\% (293/494). Krejie and Morgan (1970) suggested for a total population of 500, the sample size would be 217. Based on 293 respondents, 63.5\% $(n=186)$ were female and $36.5 \%(n=107)$ were male. From the responses, $55.6 \%(\mathrm{n}=163)$ were from semester three, followed by $20.1 \%$ $(n=59)$ from semester 2 and 24.2\% ( $n=71)$. The largest age group represented was 18 to 20 years, constituting approximately $95.5 \%(\mathrm{n}=277)$. The results of the analysis are described in Table 2.

Table 2: Demographic Profile of Respondents

\begin{tabular}{llc}
\hline & N & Percentage \\
\hline Gender & & \\
Female & 186 & $63.5 \%$ \\
Male & 107 & $36.5 \%$ \\
\hline Semester in college & & \\
One & 59 & $20.1 \%$ \\
Two & 71 & $24.2 \%$ \\
Three & 163 & $55.6 \%$ \\
\hline
\end{tabular}

\section{Hypotheses Testing}

The relationship between the dimensions of UTAUT and behavioural intention was tested with multiple regressions. The results of the analysis are depicted in Table 3. 
Volume 3 Issue 8 (March 2021) PP. 182-195 DOI: 10.35631/IJMOE.380015

Table 3: Result from Regression Analysis

\begin{tabular}{lccc}
\hline \multicolumn{1}{c}{ Hypotheses } & Std. $\boldsymbol{\beta}$ & T & Results \\
\hline H1: Performance expectancy - behavioural intention & 0.567 & 19.535 & Supported \\
H2: Effort expectancy - behavioural intention & 0.590 & 20.466 & Supported \\
H3: Social influence - behavioural intention & 0.561 & 19.279 & Supported \\
H4: Behavioural intention - student use behaviour & 0.567 & 21.738 & Supported \\
H5: Facilitating condition - student use behaviour & 0.590 & 18.838 & Supported \\
\hline $\mathrm{R}^{2}$ & 0.678 & & \\
Adj. R & 0.675 & & \\
F-Change & 107.411 & & \\
\hline
\end{tabular}

Note: $\mathrm{N}=239, * * p<0.01$

The analysis revealed that performance expectancy, effort expectancy and social influence significantly contributed to the prediction of behavioural intention. Effort expectancy having the biggest impact $(\beta=0.338, t=7.502)$, followed by performance expectancy and social influence. Therefore, $\mathrm{H} 1, \mathrm{H} 2$ and $\mathrm{H} 3$ are fully supported. $\mathrm{H} 4$ postulated that behavioural intention significantly influences student behaviour was subjected to regression analysis. As summarizes in Table 3, behavioural intention had a positive impact on student behaviour $(\beta=0.567, p<0.001)$. For the relationship between facilitating conditions and student behaviour, the former was entered as the predictor and the latter as the variable. Finding shows that facilitating conditions had a positive impact on student behaviour $(\beta=0.590$, $\mathrm{p}<0.001)$. Thus, $\mathrm{H} 4$ and H5 are fully supported.

To see the impact of voluntariness of use as a moderator in each relationship in the proposed framework, Table 4 were created. As can be seen from Table 4, Model 1 and Model 2 are significant and model 3 and model 4 are insignificant. Thus, the complete hypotheses are shown in Table 5. Based on overall analysis, hypothesis $H 1, H 2, H 3, H 4, H 5, H 6 a$ and $H 6 b$ are supported and $H 6 c$ and $H 6 d$ are rejected.

Table 4: Summary of Logistics Regression Models Testing Significance of Main Interactions Effects of UTAUT-Related Scales and Voluntariness of Use

\begin{tabular}{llccc}
\hline Model & & Beta & SE (beta) & $P$ value \\
\hline Model 1 & Performance & 0.375 & 0.129 & 0.004 \\
& expectancy & -1.341 & 0.344 & 0.000 \\
& Voluntariness of Use & 0.322 & 0.98 & 0.001 \\
& Voluntariness of Use x & & \\
& Performance & & & \\
Model 2 & expectancy & & 0.121 & 0.000 \\
& Effort expectancy & 0.433 & 0.314 & 0.001 \\
& Voluntariness of Use & -1.034 & 0.920 & 0.004 \\
& Voluntariness of Use x & 0.270 & & \\
Model 3 & Effort expectancy & & & 0.000 \\
& Social Influence & 0.554 & 0.129 & 0.011 \\
& Voluntariness of Use & -0.848 & 0.331 & 0.072
\end{tabular}




\section{Model 4}

Social Influence

$\begin{array}{lccc}\text { Facilitation Conditions } & 0.642 & 0.144 & 0.000 \\ \text { Voluntariness of Use } & -0.864 & 0.430 & 0.045 \\ \text { Voluntariness of Use x } & 0.145 & 0.107 & 0.178 \\ \text { Facilitation Conditions } & & & \end{array}$

Table 5: Hypotheses Result

\begin{tabular}{clc}
\hline Hypotheses & Regression Path & Result \\
\hline$H 1$ & PE $\rightarrow$ BI & Supported \\
$H 2$ & EE $\rightarrow$ BI & Supported \\
$H 3$ & SI $\rightarrow$ BI & Supported \\
$H 4$ & BI $\rightarrow$ SB & Supported \\
$H 5$ & FC $\rightarrow$ SB & Supported \\
$H 6 a$ & PE $\rightarrow$ VOU $\rightarrow$ BI & Supported \\
$H 6 b$ & EE $\rightarrow$ VOU $\rightarrow$ BI & Supported \\
$H 6 c$ & $\mathrm{SI} \rightarrow$ VOU $\rightarrow$ BI & Not Supported \\
$H 6 d$ & FC $\rightarrow$ VOU $\rightarrow$ SB & Not Supported \\
\hline
\end{tabular}

\section{Discussions of Findings}

It was found that performance expectancy, effort expectancy and social influence are significant with students' behaviour intention. The students' behaviour intention and facilitating conditions also found have significant impact on students' use behaviour. These findings concur with the findings of previous researchers (Almaiah et al., 2019; Chao, 2019; Jayaseelan et al., 2020; Khechine, \& Augier, 2019; Kumar \& Bervell, 2019; Padhi, 2018; Rabaai', 2017; Raza et al., 2020; Salloum \& Shaalan, 2018). As expected, effort expectancy has a strong relationship with behavioural intention. The findings are consistent with earlier studies that agreed there is a relationship between effort expectancy and behavioural intention (Chao, 2019). As Kaliisa et al. (2019) mentioned earlier, the easier using the technology, the higher possibility for the student to accept the technology. Therefore, the educators need to ensure that the students could access the Google Classrooms, as well as the materials that posted in the Google Classroom, are easy to access by the student, simple and fun.

Instead of effort expectancy, performance expectancy also shows significant relationship with behavioural intentions. As discussed in previous studies, effort expectancy has become one of the factors that contribute to the behaviour intention (Chao, 2019; A Raman \& Rathakrishnan, 2020). The finding reveals that social influence has a positive relationship with behavioural intention and the result in line with other scholars (Kaliisa et al.,2019; Liu et al., 2019). Thus, social influence becomes one of the important factors that determine student behaviour in using Google Classroom. The findings provide the support that behavioural intention and facilitating conditions are the factors that encourage the student use behaviour. Undoubtedly, the significant effect of behavioural intention towards student behaviour in 


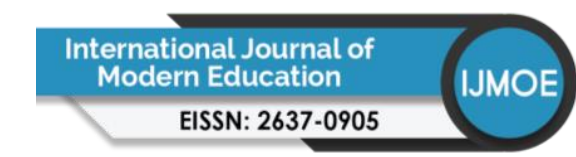

Volume 3 Issue 8 (March 2021) PP. 182-195 DOI: 10.35631/IJMOE.380015

actual use was discussed in previous studies (Al-Maroof \& Al-Emran, 2018; Almaiah et al., 2019). In addition, this study confirmed that facilitating conditions could influence the student use behaviour of the Google Classroom. A student who belief towards the availability of the Google Classroom would use the Google Classroom.

The findings of this study could provide useful insight to the lecturer or educator to encourage the acceptance and usage of the Google Classroom. They can focus on the usefulness and benefits of the Google Classroom and encourage their students to use it wisely effective online learning medium. They should provide the students with information and training on how to fully utilize the Google Classroom; thus, the students' perceive that the applications will be useful for them in achieving better results. The result of moderation effect of voluntariness of use is in line with other previous literature (Bervell \& Arkorful, 2020; Jayaseelan et al., 2020; Maruping, Bala, Venkatesh \& Brown, 2017; Yang, Feng \& MacLeod, 2019). The educators have to play their role to educate the students well about the functions of this application. Therefore, they could manage their learning time and the application give benefit for them (Ramayah, 2010).

\section{Conclusion, Limitations and Future Research}

The findings of this study show clearly that the Google Classroom has given positive impact to the students' performance internally. Google Classroom is found reliable to be used as the medium of education. All linear regression is found significant to the students use behaviour and the voluntariness of use been moderate to the performance expectancy and effort expectancy with the behaviour intention and cause the use of behaviour stronger in question. The behavioural intention and facilitating condition positively influence the students use behaviour. The findings contribute to the UTAUT theory from the student perspectives from the Malaysia Community College. The similarities with other previous studies could significantly contributes new results and strengthen the existing body of knowledge in the conceptual and empirical researches. The results of this study cannot be generalized since the questionnaire passed to the specific program offered by Malaysia Community College. However, it is suggested to extend this study to the larger sample of respondents from other programs offered in Malaysia Community College. As this study focus from the point of view of the students, therefore, educator's acceptance in using Google Classroom also can be investigated in future studies. Other online applications also can be discussing as a medium of teaching and learning for more interactive and effective way of teaching. The results provide useful insight on the willingness to use and use of Google Classroom among Malaysia Community College students. It is hoped that results from this study can be used as a guideline for educators to focus on and strategize their teaching methods as well as dealing and adapting the new norm of the education environment.

\section{References}

Abd Manan, N. Z., \& Hanafi, H. F. (2019). Google Classroom : Student's Acceptance Using UTAUT Model. JAPPA Journal, 1(1), 64-72.

Ajzen, I. (2015). Consumer attitudes and behavior: the theory of planned behavior applied to food consumption decisions. Rivivista Di Economia Agraria, 2(AnnoLXX), 121-138. https://doi.org/10.13128/REA-18003

Al-Maroof, R. A. S., \& Al-Emran, M. (2018). Students Acceptance of Google Classroom: An Exploratory Study Using PLS-SEM Approach. International Journal of Emerging Technologies in Learning, 13(6), 112-123. https://doi.org/10.3991/ijet.v13i06.8275 


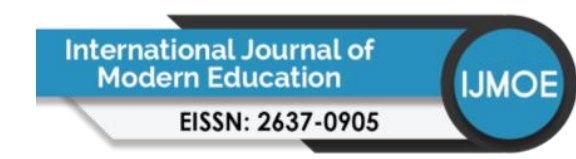

Volume 3 Issue 8 (March 2021) PP. 182-195 DOI: 10.35631/IJMOE.380015

Almaiah, M. A., Alamri, M. M., \& Al-Rahmi, W. (2019). Applying the UTAUT Model to Explain the Students' Acceptance of Mobile Learning System in Higher Education. IEEE Access, 7, 174673-174686. https://doi.org/10.1109/ACCESS.2019.2957206

Anderson, J. E., \& Schwager, P. H. (2004, February). SME adoption of wireless LAN technology: applying the UTAUT model. In Proceedings of the 7th annual conference of the southern association for information systems (Vol. 7, pp. 39-43).

Bervell, B., \& Arkorful, V. (2020). LMS-enabled blended learning utilization in distance tertiary education: establishing the relationships among facilitating conditions, voluntariness of use and use behaviour. International Journal of Educational Technology in Higher Education, 17(1), 1-16.

Chao, C. M. (2019). Factors determining the behavioral intention to use mobile learning: An application and extension of the UTAUT model. Frontiers in psychology, 10, 1652.

Dwivedi, Y. K., Rana, N. P., Chen, H., \& Williams, M. D. (2011, September). A Metaanalysis of the Unified Theory of Acceptance and Use of Technology (UTAUT). In IFIP international working conference on governance and sustainability in information systems-managing the transfer and diffusion of it (pp. 155-170). Springer, Berlin, Heidelberg.

Fishbein, B. M., \& Ajzen, I. (2010). Predicting and Changing Behavior: The Reasoned Action Approach. Taylor \& Francis Group, London. Retrieved from www.taylorandfrancis.com

Han, J., \& Conti, D. (2020). The use of UTAUT and post acceptance models to investigate the attitude towards a telepresence robot in an educational setting. Robotics, 9(2). https://doi.org/10.3390/ROBOTICS9020034

Jayaseelan, R., Koothoor, P., \& Pichandy, C. (2020). Technology Acceptance By Medical Doctors In India: An Analysis With UTAUT Model. system, 7, 31.

Kaliisa, R., Palmer, E., \& Miller, J. (2019). Mobile learning in higher education: A comparative analysis of developed and developing country contexts. British Journal of Educational Technology, 50(2), 546-561. https://doi.org/10.1111/bjet.12583

Khechine, H., \& Augier, M. (2019). Adoption of a social learning platform in higher education: an extended UTAUT model implementation. In Proceedings of the 52nd Hawaii International Conference on System Sciences.

Kumar, J. A., \& Bervell, B. (2019). Google Classroom for mobile learning in higher education: Modelling the initial perceptions of students. Education and Information Technologies, 24(2), 1793-1817. https://doi.org/10.1007/s10639-018-09858-Z

Liu, D., Maimaitijiang, R., Gu, J., Zhong, S., Zhou, M., Wu, Z., ... Hao, Y. (2019). Using the Unified Theory of Acceptance and Use of Technology (UTAUT) to investigate the intention to use physical activity apps among university students in Guangzhou, China: Cross-sectional survey. Journal of Medical Internet Research, 21(9), 1-9. https://doi.org/10.2196/13127

Maruping, L. M., Bala, H., Venkatesh, V., \& Brown, S. A. (2017). Going beyond intention: Integrating behavioral expectation into the unified theory of acceptance and use of technology. Journal of the Association for Information Science and Technology, 68(3), 623-637.

Mohd Ariffin, N. H., Ahmad, F., \& Haneef, U. M. (2020). Acceptance of Mobile Payments by Retailers Using UTAUT Model. Indonesian Journal of Electrical Engineering and Computer Science, 19(1), 149-155. https://doi.org/10.11591/IJEECS.V19.I1.PP149155 


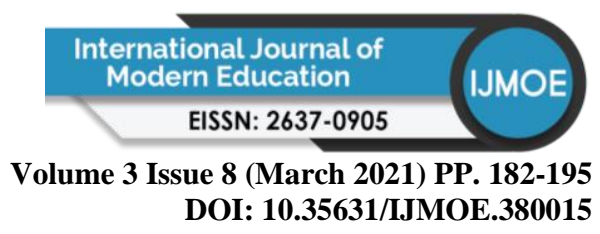

Moore, G. C., \& Benbasat, I. (1991). Development of an instrument to measure the perceptions of adopting an information technology innovation. Information Systems Research, 2(3), 192-222.

Mubuke, F., Masaba, A. K., Ogenmungu, C., \& Kituyi, G. M. (2017). Examining the Effect of Facilitating Conditions as An Imperative Input in Enhancing the Intention To Use Mobile Learning systems in Universities. Global Journal of Computers \& Technology, 6(1), 336-343. $\quad$ Retrieved from http://www.irrodl.org/index.php/irrodl/article/view/2203

Octaberlina, L. R., \& Muslimin, A. I. (2020). EFL Students Perspective Towards Online Bearning barriers and Alternatives Using Moodle/Google Classroom during Covid-19 Pandemic. International Journal of Higher Education, 9(6), 1-9. https://doi.org/10.5430/ijhe.v9n6p1

Okmawati, M. (2020). The Use of Google Classroom During Pandemic. Journal of English Language Teaching, 9(2), 438. https://doi.org/10.24036/jelt.v9i2.109293

Padhi, N. (2018). Acceptance and usability of OER in India: An investigation using UTAUT model. Open Praxis, 10(1), 55-65.

Rabaa'i, A. A. (2017). The use of UTAUT to investigate the adoption of e-government in Jordan: a cultural perspective. International Journal of Business Information Systems, 24(3), 285-315.

Rahi, S., Abd. Ghani, M., Alnaser, F. M. I., \& Ngah, A. H. (2018). Investigating the role of unified theory of acceptance and use of technology (UTAUT) in internet banking adoption context. Management Science Letters, 8(3), 173-186. https://doi.org/10.5267/j.msl.2018.1.001

Raman, A, \& Rathakrishnan, M. (2020). Blended Learning Via Google Classroom: English Language Students Experience Based on Utaut Model and Flow Theory. Hamdard Islamicus, (June).

Raman, Arumugam, Singh, P. K. K., Rathakrishnan, M., \& Ismail, S. N. (2020). Blended Learning Via Google Classroom: English Language Students Experience Based on Utaut Model and Flow Theory. Hamdard Islamicus, (June). Retrieved from https://www.researchgate.net/profile/Arumugam_Raman/publication/340809895_BL

ENDED_LEARNING_VIA_GOOGLE_CLASSROOM_ENGLISH_LANGUAGE_S TUDENTS_EXPERIENCE_BASED_ON_UTAUT_MODEL_AND_FLOW_THEO RY/links/5e9edda1a6fdcca7892c861c/BLENDED-LEARNING-VIA-GOOGLECLASSROOM-

Ramayah, T. (2010). The Role of Voluntariness in Distance Education Students' Usage of a Course Website. Turkish Online Journal of Educational Technology-TOJET, 9(3), 96105.

Raza, S. A., Qazi, W., Khan, K. A., \& Salam, J. (2020). Social Isolation and Acceptance of the Learning Management System (LMS) in the time of COVID-19 Pandemic: An Expansion of the UTAUT Model. Journal of Educational Computing Research. https://doi.org/10.1177/0735633120960421

Salloum, S. A., \& Shaalan, K. (2018). Factors Affecting Students' Acceptance Of E-Learning System In Higher Education Using UTAUT And Structural Equation Modeling Approaches. In International Conference on Advanced Intelligent Systems and Informatics (pp. 469-480). Springer, Cham.

Tran, T. D. (2019). An UTAUT Application-IOT Acceptance in Retail Digital Management of Information and Knowledge Systems. Universite Paris 1 Pantheon - Sorbonne. https://doi.org/10.13140/RG.2.2.28727.27047 
Volume 3 Issue 8 (March 2021) PP. 182-195 DOI: 10.35631/IJMOE.380015

Tsai, H., Compeau, D., \& Meister, D. (2017). Voluntary use of information technology: an analysis and synthesis of the literature. Journal of Information Technology, 32(2), 147-162.

Venkatesh, V., Morris, M. G., Davis, G. B., \& Davis, F. D. (2003). User Acceptance of Information Technology: Toward A Unified View. MIS Quarterly, 27, 424-478. https://doi.org/10.1006/mvre.1994.1019

Williams, M. D., Rana, N. P., \& Dwivedi, Y. K. (2015). The unified theory of acceptance and use of technology (UTAUT): A literature review. Journal of Enterprise Information Management (Vol. 28). https://doi.org/10.1108/JEIM-09-2014-0088

Yang, H. H., Feng, L., \& MacLeod, J. (2019). Understanding college students' acceptance of cloud classrooms in flipped instruction: integrating UTAUT and connected classroom climate. Journal of Educational Computing Research, 56(8), 1258-1276. 